\section{Isomerization of Poly-cis-carotenes by Chlorophyll in vivo and in vitro}

ONE of the Chlorella mutants described by Claes (strain $5 / 520)^{1}$ synthesizes in the dark certain polycis-isomers, which are described in the literature as protetrahydrolycopene $e^{2}$ and prolycopene ${ }^{3}$. In the algal cells the stereoconfiguration is sensitive to light. If oxygen is present, the procarotenes are isomerized in blue but not in red light, yielding the trans-forms in the cells. In this case light absorbed by the earotenes is presumed to be responsible for their isomerization.

Not so readily explained was the observation that in the mutant $5 / 520$ the stereoconfiguration of protetrahydrolycopene and prolycopene can become unstable also in red light, which is not absorbed by carotenes. This phenomenon requires irradiation in a nitrogen atmosphere, absence of oxygen alone being insufficient".

In view of more recent results, the isomerization of protetrahydrolycopene and prolycopene under conditions of anaerobiosis and red light appears to be sensitized by the chlorophyll present in small amounts in the dark-grown mutant. After chromatographic isolation, both procarotenes show the same behaviour in petroleum ether as in the cell, if the solutions contain some chlorophyll.

Fig. 1 shows the ehlorophyll-sensitized isomerization of protetrahydrolycopene in red light (500-W. tungsten lamp, Schott filter $R G 1$ and $K G 1$, distance of the solution from the light source about $60 \mathrm{~cm}$.). Irradiation for $2 \mathrm{hr}$. results in a change from the spectrum of protetrahydrolycopene to one predominantly that of trans-tetrahydrolycopene. If the solution contains no chlorophyll, the procarotene spectrum is scarcely changed under the same conditions of irradiation.

As in the intact cells, chlorophyll-sensitized isomerization of poly-cis-carotenes in petroleum ether is inhibited by oxygen. Fig. 2 shows the influence of aeration on the isomerization of prolycopene. The carotene solution contained chlorophyll $a$ and was irradiated with red light in the presence of nitrogen or air. Whereas the isomerization is almost at

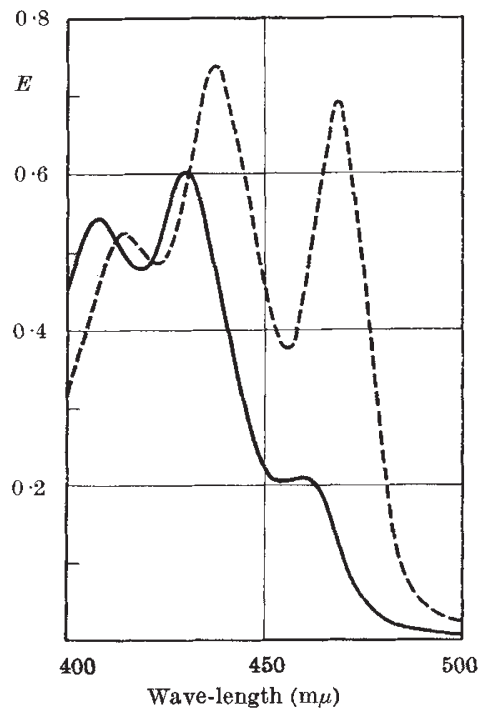

Fig. 1. Absorption spectrum of a mixture of protetrahydrolycopene $\left(6.1 \times 10^{-6} M\right)$ and chlorophyll $a\left(0.9 \times 10^{-6} M\right)$ in petroleum ether before, $2 \mathrm{hr}$, with red light

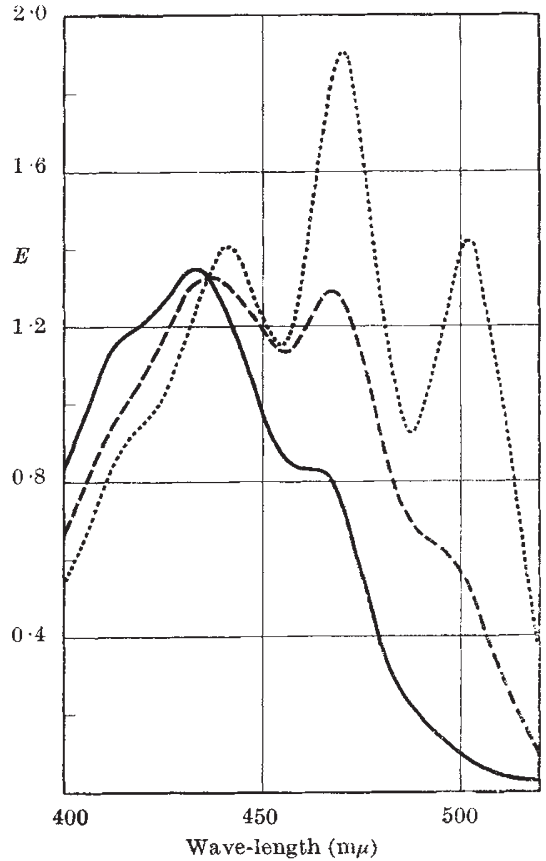

Fig. 2. Absorption spectrum of a mixture of prolycopene $\left(1 \cdot 2 \times 10^{-} M\right)$ and chlorophyll a $\left(0 \cdot 2 \times 10^{-6} M\right)$ in petroleum red light in the presence of nitrogen.

equilibrium after irradiation for half an hour in nitrogen, the presence of oxygen is inhibitory.

These findings indicate that in certain conditions (oxygen deficiency and light) the stereoconfiguration of carotenoids in the chloroplasts might be controlled by chlorophyll. The reaction is not limited to the structure of chloroplasts and can be observed outside the cell in pure solutions. Further implications necessarily await more detailed studies of chlorophyll carotenoid interactions in general.

We are indebted to Miss I. Dobrigkeit for technical assistance.

\section{H. Claes \\ T. O. M. NAKAYAMA*}

Max-Planck-Institut für Biologie, Tübingen.

* Visiting research worker supported by the National Science Foundation.

1 Claes, H., Z. Naturforsch., 11b, 260 (1956); 12b, 401 (1957).

${ }^{2}$ Trombly, H. H., and Porter, J. W., Arch. Biochem., 43, 443 (1953).

3 Zechmeister, L., Le Rosen, A., Schroeder, W. A., Polgar, A., and Pauling, I., J. Amer. Chem. Soc., 65, 1940 (1943).

* Claes, H., Z. Naturforsch., 13b, 222 (1958).

\section{Green Fluorescence of Guanidinium Compounds with Ninhydrin}

CURRENTLY available methods for the determination of creatine and other guanidinium compounds are based on non-specific chromogenic reactions. These include the Jaffe, the diacetyl $\alpha$-naphthol, the Sakaguchi, and the sodium nitroprusside-potassium ferrocyanide reactions. Determination of the individual members of the guanidinium group requires chromatographic separation, chemical degradation, or specific enzymatic destruction of the compound. In a search for a more satisfactory reaction for detection of guanidinium compounds than is at present afforded by chromogenic reactions we have found that ninhydrin $(1,2,3$-indantrione hydrate) in 